\title{
Um resgate histórico sobre a bacia hidrográfica no contexto do imperialismo dos séculos XVII e XVIII. Os casos da França e da Inglaterra
}

\author{
Un rescate histórico sobre la cuenca hidrográfica en el contexto \\ del imperialismo de los siglos XVII y XVIII. Los casos de \\ Francia y de Inglaterra
}

\section{A Historical rescue about hydrographic basins in the context of imperialism in the seventeenth and eighteenth centuries. France and England}

\author{
Antonio Vitte \\ acvitte@ige.unicamp.br \\ Universidade de Campinas
}

\begin{abstract}
Resumo: O objetivo do presente artigo é resgatar o momento histórico em que a bacia hidrográfica passa a ser considerada como uma unidade espacial de planejamento e de regionalização do território. A bacia hidrográfica é cientificamente eleita como estrutura de diferenciação morfológica da crosta terrestre a partir do século XVII, pari passu a migração do sistema-mundo do mediterrâneo para o nordeste da Europa, momento em que se efetiva a luta imperialista entre a França e a Grã-Bretanha.
\end{abstract}

Palavras-chave: Bacia Hidrográfica. Região Natural. Imperialismo. Mapeamento. Geopolítica.

Resumen: El objetivo de este artículo es rescatar el momento hsitórico en el cual la cuenca hidrográfica ha sido considerada como una unidad espacial de planificación y de regionalización del territorio. La cuenca hidrográfica fue cientificamente elejida como una estructura de diferenciación morfológica de la corteza terrestre a partir del siglo XVII, pari passu la migración del sistema-mundo del mediterraneo para el nordeste de Europa, momento en el cual se efectivava la lucha imperialista entre Francia y Gran Bretania.

Palabras-clave: cuenca hidrográfica; región natural; imperialismo; cartografía; geopolítica.

Abstract: The purpose of this article is to rescue the historical moment in which hydrographic basins turn out to be considered as spatial units for planning and regionalization of the territory. Hydrographic basins have scientifically been chosen as structure of morphological differentiation of the Earth's crust since the seventeenth century pari passu the migration of the world-system of the Mediterranean up to Northern Europe in a time of effective imperialist struggle between France and Great Britain.

Keywords: Hydrographic Basin. Natural Region. Imperialism. Cartographic. Geopolitics. 


\section{INTRODUÇÃO}

O objetivo deste ensaio é realizar um resgate histórico sobre o uso da bacia hidrográfica pela sociedade, demonstrando que a sua ascensão como conceito estruturador da análise geográfica atendeu antes a uma função geopolítica explícita. O contexto histórico e econômico em que a bacia hidrográfica é utilizada como organizadora das feições da crosta terrestre é a luta imperialista entre França e Inglaterra, que se desenrolou particularmente entre os séculos XVII e XVIII. Concomitante a organização deste novo sistema-mundo, a bacia hidrográfica como conceito geográfico fundador da interpretação da dinâmica da natureza na crosta terrestre, também teve um importante papel na formação do conceito de região natural. Conceito este que é formado concomitante as discussões sobre raça, a relação raça-natureza-cultura, discussões motrizes para o nascimento da geografia humana e da antropologia.

Este resgate histórico se justifica pelo fato de serem escassas as referências em manuais de história do pensamento geográfico e de geografia física sobre a formação social do conceito de bacia hidrográfica, em especial sobre o seu papel no desenvolvimento histórico e econômico do sistema-mundo. Ou seja, é um tema que nos leva a refletir sobre a produção do conceito de natureza após a revolução científica moderna, que foi gestada em um ambiente urbano e viabilizada pela perda de centralidade do mediterrâneo para o nordeste da Europa na conformação do novo sistema-mundo.

\section{A QUESTÃO REGIONAL NO IMPERIALISMO NOS SÉCULOS XVII E XVIII}

Segundo Sahlins (1990) no século XVII os geógrafos de Richelieu já vinham desenvolvendo a ideia de fronteira natural, concepção que funcionou como um cimento ideológico e que permitiu ao Antigo Regime expandir suas fronteiras no Atlântico, e em direção aos Alpes e aos Pireneus, além da anexação da Alsácia e da Lorena ${ }^{1}$. Citando o historiador Albert Sorel, Sahlins (1990) diz que "geography determined French policy", onde a noção de regiões e fronteiras naturais materializava uma concepção teleológica da história francesa.

Ainda segundo Sahlins (1990, p.1425):

History and geography formed part of a political culture that drew its language and images from the work of experts like Labbe-geographers, cartographers, and historians most often in the service of the crown. These ideas of natural and historical frontiers constituted neither an "interest" nor an "ideology" but a belief that gave shape to an imagined national space, bounded and unified, in seventeenth-century France.

Em 1652, o jesuíta Jean Françoise expressou, em seu livro Science of Geography, o papel das montanhas e dos rios como fortificações naturais, elementos da natureza que

1 Para Gaston Zeller, esta questão das regiões e das fronteiras naturais no pensamento social francês foi tão forte, que interferiu profundamente na capitulação da França durante a II Guerra Mundial. ZELLER, G. Histoire d'une idee fausse. Revue de synthèse, n.11/12, 1936, p. 115-131. 
foram imediatamente difundidos como fronteiras naturais de um país (SAHLINS, 1990). Esta colocação estava atrelada ao imaginário medieval francês, segundo o qual desde o século XIII a fronteira natural aparecia sempre como um símbolo dinâmico (SAHLINS, 1990), estando associada às montanhas e rios que davam o sentimento de unidade e pertencimento ao povo francês.

Na Idade Moderna, este sentimento se consolidou a ponto de as fronteiras e as regiões naturais da França não serem somente os limites da administração do Antigo Regime, mas se confundirem teologicamente com o próprio corpo do rei.

É neste momento que surgiu a cartografia das regiões e das fronteiras naturais, produzindo uma imagem estetizada do território, onde os rios e as montanhas simbolizavam a dinâmica do reino e ao mesmo tempo a sua perpetuação através dos tempos. A partir deste momento passaram a ser produzidos atlas temáticos sobre o território francês, como a Atlas Comercial da França, produzido por Nicolas Sanson (1600-1667), considerado oficialmente o primeiro cartógrafo do reino (PASTOUREAU, 1980).

Neste contexto cultural e geopolítico solidificaram-se na cultura francesa as noções de fronteira e de região natural, de acordo com as quais os rios e as montanhas eram os representantes naturais da grandeza da nação francesa. Assim, em 1748, Montesquieu associou ao determinismo geográfico as características das fronteiras naturais, enquanto que para David Hume a determinação moral do caráter nacional era dependente da fronteira natural (GAY, 1973).

De 1660 a 1756, Cassini realizou o levantamento geodésico e cartográfico da França, culminando com a determinação do meridiano de Paris. Mas em 1680 ele havia determinado os limites naturais do território francês, que coincidiam com cadeias de montanhas. Com isto, Cassini cristalizou na linguagem cartográfica o sentimento francês de domínio de um espaço contínuo (BROC, 1978).

Logo após o Tratado de Viena de 1738, a França incorporou a Lorena e a Córsega, desse modo, as noções de fronteira e de região natural foram estrategicamente utilizadas no contexto da disputa geopolítica.

O desenvolvimento cartográfico centrado no Observatório de Paris, associado às medições geodésicas inicialmente levadas a cabo por Cassini, propiciaram uma importante modernização administrativa, como a reforma burocrática que, utilizando-se dos trabalhos de mapeamento sistemático do território francês, racionalizou a administração do Estado e ao mesmo tempo pode exercer um controle político eficiente sobre o território. Assim, foram realizados extensos levantamentos topográficos objetivando determinar os limites municipais e provinciais, concomitante a um levantamento estatístico profundo sobre a população, as moradias e as condições administrativas locais (TRENARD, 1985).

Com este levantamento geodésico, topográfico e censitário, em 1780 o governo francês realizou uma série de tratados com os reinados vizinhos, particularmente com os reinos de Savoia e de Espanha, onde foram utilizados como critérios para o estabelecimento da fronteira entre a França e Savoia os divisores de bacias hidrográficas. No caso espanhol, o critério natural foram os Pirineus. Já no caso dos limites entre a França e os reinos e principados alemães a discussão foi tensa, uma vez que além da questão da 
anexação da Lorena pelo Estado francês, os principados não aceitavam uma delimitação física, como as montanhas ou os divisores de água como limites naturais. A fronteira natural entre a França e os principados germânicos era dada pelo rio Ruhr. Os principados questionavam a delimitação, pois além da riqueza mineral na bacia hidrográfica do Ruhr, a dinâmica geomorfológica era marcada por constantes inundações, com intensa dinâmica de migração do canal principal. Esta característica era vista como um problema geopolítico pelos principados, uma vez que o temor era de perda de área territorial, já que a erosão fluvial do Ruhr nos territórios dos principados era intensa, com consequente deposição dos sedimentos no território francês. Segundo Sahlins (1990), este problema nunca foi bem resolvido entre a França e os principados germânicos e evoluiu para problemas geopolíticos no século XIX e XX.

\section{A GÉOGRAPHIE PHYSIQUE DE PHILLIPPE BAUCHE: A BACIA HIDROGRÁFICA E A RACIONALIZAÇÃO DO TERRITÓRIO FRANCÊS}

Em 1730 o rei francês reconheceu a importância do trabalho do geógrafo Phillipe Bauche (1707-1778) outorgando-lhe o título de geógrafo real, que juntamente com o cartógrafo Guillaume Delisle vinham produzindo mapeamentos referentes ao Canal da Mancha e as colônias da França na América e na África.

Em 1740, Paris sofreu uma enorme inundação, na tentativa de resolver este problema, Bauche e Delisle realizaram um mapeamento semidetalhado da capital francesa, em que distinguiram as áreas de topo e as de fundo de vale, argumentando que a inundação estava relacionada às características dos vales fluviais, que segundo eles eram as áreas preferenciais para o escoamento da drenagem perene e intermitente (figura 1). Para Bauche e Delisle, estes canais eram produto do escoamento da água sobre a superfície, que gerava canais e topos, portanto, diferenciações topográficas e geomorfológicas derivadas da erosão.

No ano de 1744, Bauche apresentou a Academie des Sciences dois mapeamentos, o primeiro tratou do canal da Mancha e o segundo sobre o papel das bacias hidrográficas na esculturação do relevo francês ${ }^{2}$. Para Bauche, a diferenciação do relevo era o produto daquilo que ele chamava de cadeias de montanhas que eram esculturadas pelas drenagens, o que permitiria regionalizar o território francês em regiões naturais, que para Bauche nada mais eram que bacias hidrográficas (figura 2). Por analogia, Bauche advogava que não somente a crosta emersa poderia ser regionalizada por bacias hidrográficas, mas que estas mesmas cadeias montanhosas também dividiam os oceanos em Atlântico, mar das Índias (oceano Índico) e o grande mar (oceano Pacífico). Demonstrando com isto que as bacias hidrográficas e as cadeias montanhosas que resultavam da esculturação fluvial poderiam ser utilizadas como referencial lógico para o entendimento e a racionalização da natureza na superfície terrestre.

2 Segundo Debarbieux (2009), este trabalho de Bauche foi publicado cinco anos antes de Buffon publicar a Teoria da Natureza. Segundo o próprio Buffon, o mesmo foi despertado para o papel das montanhas da diferenciação do relevo e principalmente nas espécies a partir do trabalho de Bauche. 
Figura 1. Planta hidrográfica da cidade de Paris, elaborada por Bauche e Deslile em 1740.

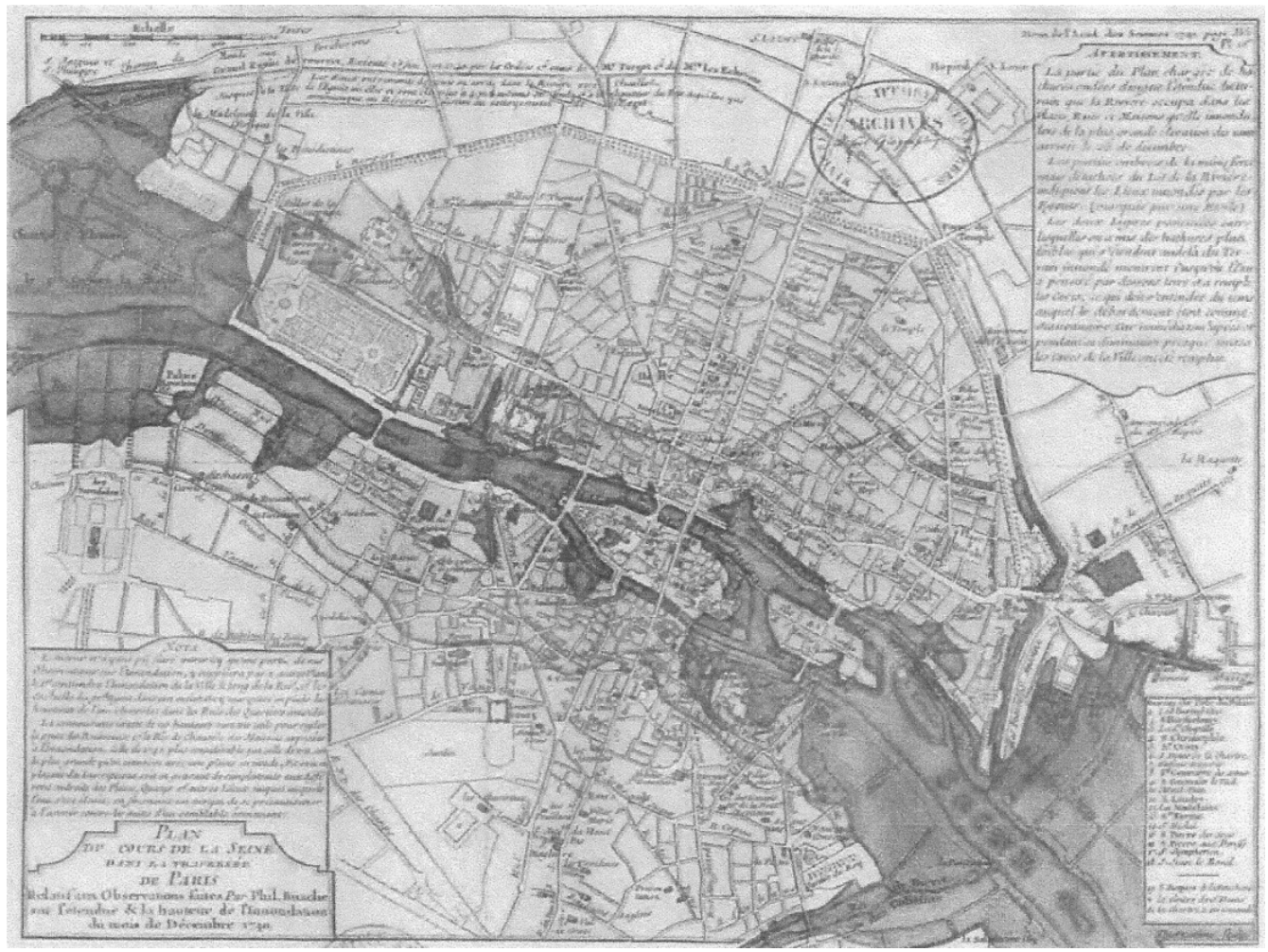

Fonte: LAGARDE (1990, p. 27)

Figura 2. As regiões naturais do território francês segundo Bauche (1744).

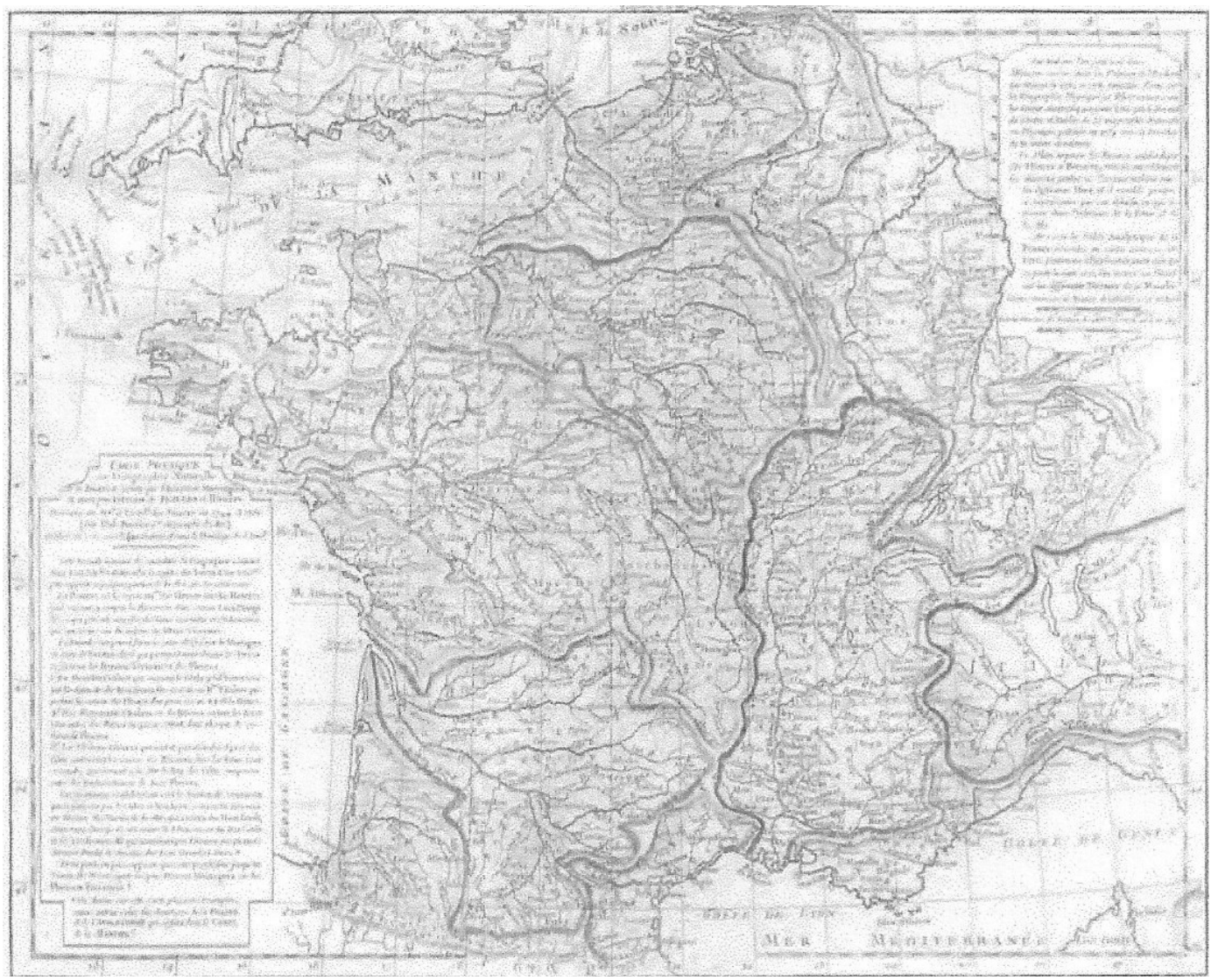

Fonte: LAGARDE (1990, p.29). 
Em 1752, Bauche apresentou a Academie des Sciences o livro Essai de géographie physique, ou l'on propose des vues générales sur l'espèce de Charpente du Globe, composée des Chaînes de Montagnes qui traversent les Mers comme les Terres, avec quelques considérations particulières sur les différents Bassins de la Mer, et sur sa configuration intérieure (DEBARBIEUX, 2009). Neste livro, Bauche defendeu que as diferenciações da morfologia da crosta seriam produto da dissecação fluvial, cujo resultado era bacias hidrográficas (figura 3) compostas por topos, vertentes e fundos de vale. As bacias hidrográficas poderiam ser delimitadas em cartas topográficas e o conjunto de bacias hidrográficas sob mesmas condições climáticas e geológicas permitiria a regionalização do território em regiões naturais. Para esta afirmação, Bauche utilizou-se do mapeamento mineralógico da França realizado por Guettard em 1746, que demonstrou que a distribuição dos minerais na França estava relacionada às litologias e à dissecação do relevo, comandada pelos rios (DEBARBIEUX, 2009).

Figura 3- Proposta de Bauche (1754), para a regionalização dos continentes em bacias hidrográficas.

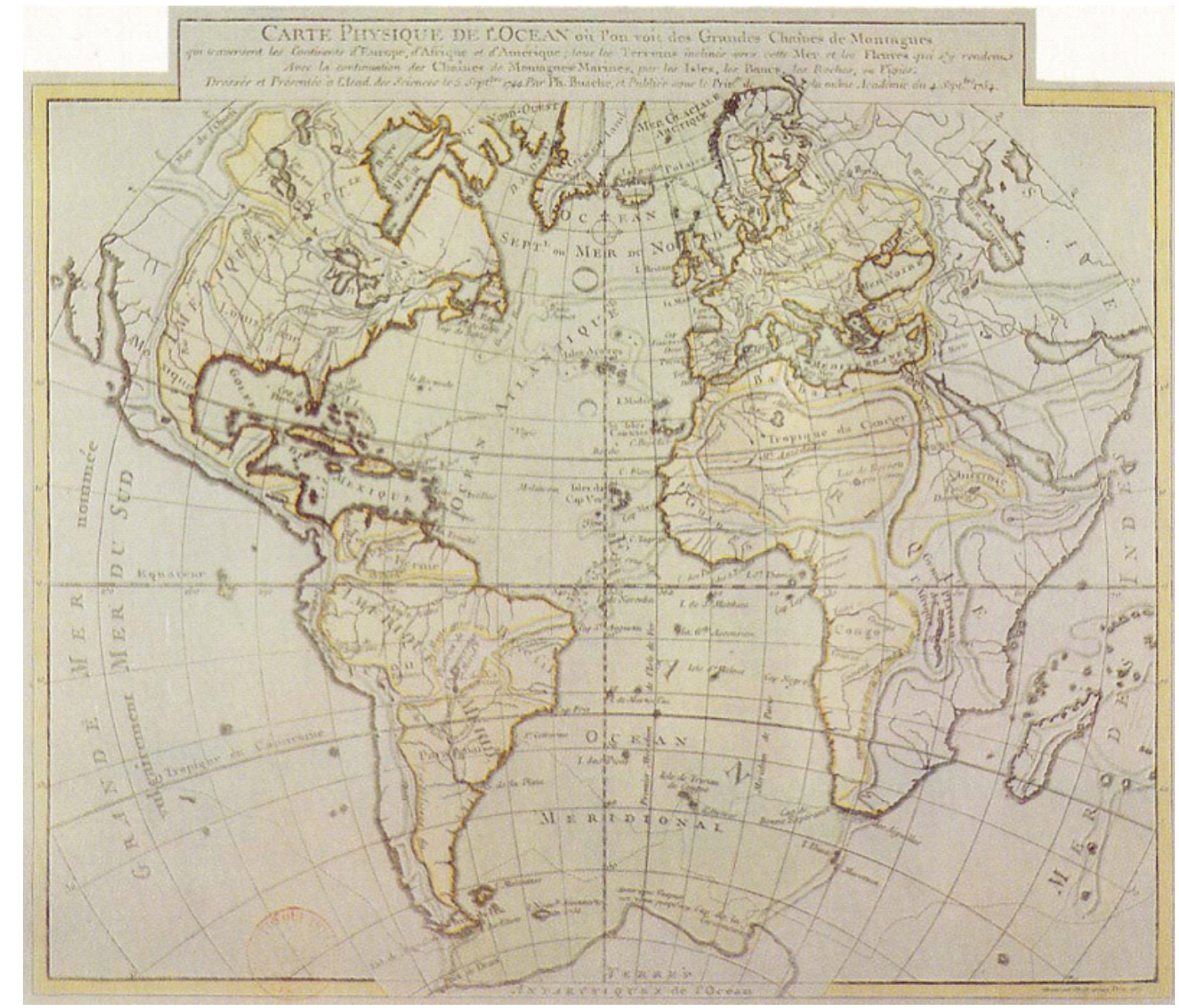

Fonte: DEBARBIEUX (2009, p. 91).

O Essai de Géographie Pysique, de P. Bauche representou não somente a evolução de uma tradição no pensamento geográfico francês dos séculos XVII e XVIII, mas também a sua organização, assim como as suas premissas serviram como elemento estratégico para 
a racionalização sobre o espaço e o território. Primeiramente Bauche considerou que as formas de relevo na superfície da Terra apresentavam organização e distribuição espacial dividida em cadeias de montanhas e bacias hidrográficas, que representariam, segundo ele, um ordenamento lógico para a distribuição dos objetos naturais no espaço.

Para Buache (apud DEBARBOEUX, 2009, p. 98):

I thought that [...] I had to use the clues left by the rivers. We can't deny that the origins of rivers and streams naturally indicate the height of the terrains where they source their water to nourish and fertilize the lands they cross as they descend from the high places, whether it be by steeper or shallower slopes, until they empty themselves into the sea. Neither can we doubt the liaison and the relationship that mountains have with rivers.

Para a concepção de distribuição, relação e ordenamento dos objetos naturais na superfície da Terra, Bauche tomou como referência a noção de espaço geométrico de Descartes, onde o espaço terrestre seria um sistema de referências de pontos, permitindo desta forma que o mesmo fosse cartografado.

Segundo Bauche, os objetos naturais não apresentariam uma distribuição aleatória na superfície da Terra e as formas estariam sempre lógica e geneticamente conectadas, como no caso do topo das montanhas com o canal dos rios; com isto, Bauche inferia que as montanhas eram úteis não somente para a delimitação das regiões e das fronteiras naturais, mas também para a exploração mineral (DEBARBOEUX, 2009).

Para o mapeamento e a utilização dos recursos minerais das montanhas, Bauche pressupôs um encadeamento metodológico, destacando a realização de trabalhos de campo e a utilização de técnicas matemáticas para o cálculo do gradiente, do volume e das altitudes das montanhas. Esta regra metodológica não somente auxiliaria, segundo Bauche, na localização e no mapeamento das jazidas minerais (DEBARBOEUX, 2009).

Assim, Phillippe Bauche, ao propor uma cartografia para o território francês com destaque para a sua divisão em bacias hidrográficas, permitiu que elas, as bacias, fossem concebidas como unidades lógicas que deveriam ser utilizadas para a delimitação de regiões naturais, preconizando, segundo Gomes (1995), a concepção de que o ambiente teria certo domínio sobre a orientação do desenvolvimento da sociedade.

Enfim, a partir das noções de fronteira e de região natural, a França racionalizou e ao mesmo tempo purificou o seu espaço, fatores que viabilizaram a unificação política, fiscal e econômica de seu território (NOEL, 1966); características estas que foram revolucionárias no contexto europeu e serviram como modelo para outros países, como por exemplo, a Grã-Bretanha.

\section{O USO DA BACIA HIDROGRÁFICA E DA REGIÃO NATURAL PELA INGLATERRA}

Na Grã-Bretanha, a partir de meados do século XVIII, a concepção de Bauche sobre a esculturação da crosta em bacias hidrográficas, assim como a noção de região natural possibilitou uma maior racionalização sobre o uso das terras, assim como a extração de 
recursos naturais, o que levou a uma especialização regional em todas as escalas do vasto território colonial inglês.

No caso da Grã-Bretanha, a definição de um processo de regionalização geográfica dos territórios coloniais ingleses não obedeceu a uma simples aplicação do conceito de região natural como formulado na França. Este processo obedeceu a uma conjunção entre a noção de diferenciação de áreas de Varenius e em muitas situações, como no caso do território indiano, houve também a incorporação de preceitos da noção de região como formulada por Estrabão.

Enquanto na Jamaica a Grã-Bretanha não pressentia perigo de resistência da população local frente a sua política imperialista e principalmente ao perigo de cooptação desta população pela França; na Índia a situação geopolítica era diferente, pois devido ao forte desenvolvimento cultural, religioso e político que prevalecia na Índia, logo se percebeu que era forte o sentimento de pertencimento das comunidades, o que impedia o uso de ações violentas para a manutenção do domínio territorial inglês nesta região do globo.

Diante deste quadro, a maior preocupação de ordem geopolítica eram as áreas fronteiriças entre a Índia e a Ásia Central, pois devido a tradição histórica de relações comerciais e culturais que prevalecia entre as comunidades indianas com as comunidades da Ásia Central, a sensação era a de que as fronteiras da Índia com a Ásia Central eram susceptíveis as incursões dos Impérios Russo e Otomano, fato que colocava em perigo os objetivos imperiais da Grã-Bretanha naquela região asiática (OGBORN, 2004; WINCHESTER, 2004).

A saída estratégica foi a construção de uma rede articulada que envolvia diplomacia e ciência ${ }^{3}$ com forte apoio tecnológico (EDNEY, 1993, 1994). Pois na avaliação geopolítica chegou-se ao consenso de que estas regiões fronteiriças eram verdadeiros espaços de transição, pois a noção de fronteira entre as comunidades indianas e as da Ásia Central eram muito tênues, o que dificultava o controle estratégico do território. Portanto tornou-se necessário que se conhecesse profundamente e em detalhe as características naturais, culturais e econômicas do território indiano. Para isto a Grã-Bretanha procedeu a um amplo mapeamento do território indiano, em especial o fronteiriço a partir de um hibridismo entre os conceitos de região cultural conforme dado por Estrabão e o de bacias hidrográficas, formando um arquivo geográfico com informações detalhadas sobre todo o território indiano, o que resultou na primeira Atlas da Índia (EDNEY,1997).

O território indiano foi mapeado em escala 1:1.000.000, e foram utilizados modernos procedimentos geodésicos, na época representada pelo método da triangulação cartográfica $^{4}$. Este mapeamento possibilitou o planejamento estratégico sobre a disposição

\footnotetext{
3 Esta estratégia coaduna-se com a concepção de Latour $(2000,2009)$ de centros de cálculo, que envolvia não somente uma rede de cientistas e de instituições, mas também promovia a sinergia entre várias propostas científicas, técnicas e tecnológicas para a resolução de problemas práticos.

4 Segundo Edney (1997) o método da triangulação cartográfica era o viés tecnológico mais avançado da época, século XVIII. O problema inicial é que diferentemente do hemisfério norte, no hemisfério sul não há a estrela polar, o que tornava impossível o uso da triangulação cartográfica. A revolução tecnológica no uso deste método pelos ingleses deu-se com a utilização da paisagem e de sua fisiografia como referência para o estabelecimento dos pontos fixos e suas respectivas coordenadas. A partir de então, o topo de uma colina, uma casa, ou mesmo uma cachoeira poderia ser utilizado como base para o estabelecimento das medidas e a consequente representação cartográfica dos objetos naturais e humanos que compunham a paisagem.
} 
das bases militares, assim como a extração dos recursos naturais das diversas regiões da Índia, forçando a especialização de tais regiões no contexto da revolução industrial inglesa.

No entanto faltava um arcabouço metodológico que informasse não somente como coletar as informações, mas principalmente como tratá-las, ou seja, como integrá-las em uma estrutura que permitisse de fato a construção de uma visão estratégica sobre o território. Para isso, os cientistas da Royal Society ${ }^{5}$ utilizaram-se mediante algumas das propostas humboldtiana de estudos sobre a natureza. $\mathrm{O}$ tema relativo à estética foi retirado do receituário metodológico, mas foi mantida a questão da observação, da descrição, da busca de conexões, das correlações, da representação cartográfica e, entremeando todas estas etapas, o uso de instrumentos de mensuração e de coleta de informações sobre as características térmicas e hídricas da atmosfera.

Esta proposta metodológica, associada ao papel da drenagem na esculturação do relevo, gerando bacias hidrográficas e estas, quando regionalizadas pelo critério das características de clima e vegetação geravam regiões naturais. Estas eram regiões naturais, objeto de trabalho dos naturalistas da Royal Society e ao mesmo tempo permitiam o julgamento sobre o uso dos recursos naturais e as potencialidades regionais indicando em que tipo de atividade uma região deveria se especializar.

Assim, dada as suas características e propriedades as regiões naturais apresentam potencial de uso diferenciado, viabilizando assim a diversificação de uso das terras e a exploração dos demais recursos naturais.

No caso específico da Grã-Bretanha, o uso da bacia hidrográfica como critério de mapeamento e definição da regionalização dos territórios coloniais, em especial a Índia, obedeceu às particularidades da dinâmica histórica de seus territórios coloniais. Neste sentido, diferentemente do caso francês, a bacia hidrográfica foi a estrutura importante para o critério de regionalização, no entanto, para a constituição e consequente efetivação da regionalização houve a necessidade de se adotar procedimentos metodológicos híbridos, onde se procurou compatibilizar os conceitos de diferenciação de áreas de Varenius, com a noção de região cultural herdada de Estrabão, associada a diferenciação espacial da natureza dada por bacias hidrográficas. Este procedimento foi efetivado mediante a adaptação da metodologia humboldtiana, incrementada com o forte uso tecnológico advindo das modernas técnicas da geodésia e da cartografia.

Este critério híbrido de regionalização do território colonial em especial a Índia, permitiu o planejamento e o uso do território colonial indiano, a ponto de iniciar um amplo processo de migração biogeográfica forçada de espécies animais e vegetais (CROSBY,1988) com amplos impactos na cultura da natureza.

5 Diferentemente da França onde já havia a figura do geógrafo e do cartógrafo, na Inglaterra esta figura surgiu somente depois de 1838 com a criação da Royal Geographical Society. Para Gascoigne (1987) o motivador para este atraso estava fundamentado na postura política de Joseph Banks, presidente da Royal Society, para quem o fundamental era o domínio da metodologia newtoniana, fato que seria o suficiente para que o filósofo natural realizasse qualquer tipo de investigação. 


\section{CONSIDERAÇÕES FINAIS}

Historicamente, o conceito de bacias hidrográficas como unidades de planejamento se desenvolveu a partir da luta imperialista entre a França e a Grã-Bretanha a partir do século XVII. É neste caldo de expansão do sistema-mundo que as bacias hidrográficas serão alçadas a categoria de instrumentos de regionalização dos territórios nacionais, cujo caso emblemático é o francês onde a noção de bacia hidrográfica passou a ser sinônimo de região natural.

Já no caso da Grã-Bretanha, a utilização da bacia hidrográfica como unidade de planejamento e controle territorial foi amplamente utilizada para fins de manutenção da segurança dos territórios coloniais, cujo melhor exemplo foi o indiano. No entanto, devido às características e propriedades do entendimento sobre ciência e método científico, além das peculiaridades culturais, históricas, religiosas e econômicas do território indiano, a Grã-Bretanha utilizou um critério híbrido para regionalizar este território colonial.

Assim, a partir da conexão entre as noções de região natural, região cultural e bacias hidrográficas, com intenso uso da tecnologia, produziu-se um amplo arquivo geográfico sobre a natureza e a cultura nos territórios indianos. Estas informações geográficas permitiram não somente a realização de mapeamentos temáticos em detalhe, como possibilitou o planejamento estratégico de uso do território, tanto para fins de controle militar, principalmente nas fronteiras da Índia com a Ásia, mas também para uma melhor extração dos recursos territoriais, o que levou a um amplo processo de especialização da produção nas diferentes regiões hindus, atendendo aos objetivos e a nova lógica espacial imposta pela revolução industrial inglesa.

\section{REFERÊNCIAS}

BROC, Numa. La geographie des philosophes. Paris: Masson, 1978.

CROSBY, Alfred. Ecological imperialism: the biological expansion of Europe 900-1900. Cambridge: Cambridge University Press, 1988.

DEBARBIEUX, Bernard. The Mountains between corporal experience and pure rationality: the contradictory theories of Philippe Bauche and Alexander von Humboldt. In: COSGROVE, Denis; DELLA DORA, Veronica. High Places. London: Taurus Libri 2009. p.87-104.

EDNEY, Matthew. Cartography without progress: reinterpreting the nature and historical development of mapmaking. Cartographic Journal, v. 30, n. 2/3, p.54-68, 1993.

British military education, mapmaking, and military mapmindedness in the later enlightenment. Cartographic Journal, v. 31, p.14-20, 1994.

Mapping an Empire. The geographical construction of British India, 1765-1843. Chicago: Chicago University Press, 1997.

GAY, Peter (ed.). The enlightenment: a comprehensive anthology. New York: Blackwell, 1973.

GASCOIGNE, John. Science in the service of empire: Joseph Banks, the British state and the uses of science in the age of revolution. Cambridge: Cambridge University Press, 1987.

GOMES, Paulo César da Costa. O conceito de Região e sua discussão. In: CASTRO, Iná Elias et al. (Orgs.). Geografia: conceitos e temas. Rio de Janeiro: Bertrand Brasil, 1995. p. 49-76. 
LAGARDE, Lucie. Philippe Bauche, ou le premier geografe française, 1700-1773. Mappe Monde, v. 87, n. 2, p.26-30, 1990.

LATOUR, Bruno. Science in action: how to follow scientists and engineers through society. Cambridge (MA): Harvard University Press, 1987.

Ciência em ação: como seguir cientistas e engenheiros sociedade afora. São Paulo: Ed. UNESP, 2000. Jamais fomos modernos. Ensaios de antropologia simétrica. Rio de Janeiro: Editora 34, 2009.

NOEL, Jean-Francois. Les Problemes de fronteires entre la France et l'Empire dans la seconde moitié du XVIIIe siecle. Revue historique, v. 23, n. 5, p. 333-46, 1966.

OGBORN, Milles. Geographia's pen: writing, geography and the arts of commerce, 1660-1760. Journal of Historical Geography, v. 30, p. 294-315, 2004.

PASTOUREAU, Mireille. Les Atlas imprimés en France avant 1700. Imago Mundi, v. 32, p. 45-72, 1980.

SAHLINS, Peter. Natural frontiers revisited: France's boundaries since the seventeenth century. The American Historical Review, v. 95, n. 5, p.1423-1451, 1990.

TRENARD, Louis. Perceptione et delimitation de l'espace français au XVIIIe siecle. L'information historique, v. 4/7, p. 124-25, 1985.

ZELLER, Gaston. Histoire d'une idee fausse. Revue de synthèse, v.11/12, p. 115-131, 1936.

WINCHESTER, Simon. Krakatoa: o dia em que o mundo explodiu. Rio de Janeiro: Objetiva, 2004.

WITHERS, Charles. How Scotland came to know itself: geography, national identity and the making of a nation, 1680-1790. Journal of Historical Geography, v. 21, p. 371-39, 1995.

Encyclopaedism, modernism and the classification of geographical knowledge. Transactions, Institute of British Geographers, v. 21, p.275-98, 1996.

Placing the Enlightenment: Thinking geographically about the Age of Reason. Chicago: Chicago University Press, 2007. p. 45-61.

On enlightenment's margins: geography, imperialism and mapping in Central Asia, c. 1798-1838.

Journal of Historical Geography, v.39, p. 3-18, 2013. 